\title{
Intelligent GSM Based Prepaid Energy Meter in a Cashless Economy
}

\author{
Ebole Alpha F ${ }^{1}$, Kuyoro S.O. ${ }^{2}$, Aremu Idris ${ }^{3}$ \\ ${ }^{1,3}$ Computer Science Department, School Of Technology, Lagos State Polytechnic, Ikorodu Lagos, Lagos State, Nigeria \\ ${ }^{2}$ Computer Science Department, School of Computing and Engineering Sciences, Babcock University, Ilishan Remo, Ogun State, Nigeria
}

\begin{abstract}
With the current trend of Information Technology in our present time, the lot in our daily life is developing accordingly, and energy meters are no exception to this phenomenon. An intelligent GSM based prepaid energy meter is developed to be able to accurately calculate the amount of consumed energy by a certain building, display the remaining energy available from a pre-purchase of electricity, by which is done by the means of recharge through SMS service. The energy meter provide the utility company with regular status of the meter on a predefined interval, and also display a real time on the user's account update, which contributes to the retrieval of the balance of the meter, as well as keeping log of the consumed energy and remaining electricity of each user by the means of SMS. It also provide utility company the ability to send updated consumption rates according to the Time of Day Tariff (TDF) to the meter on pre-defined intervals. This paper presents a prepaid energy meter to facilitate energy consumption measurement and to know consumer's maximum demand as well to detect any bypass of voltage or current in the building. The prepaid energy meter concept is shown by Proteus 8 software simulation. The major components are AVR microcontroller, Voltage and Current transformer, LCD, Relay and a load. Electricity has become one of the basic requirements for people and widely used for domestic, industrial and agricultural purposes. The system was designed and implemented on a trivial load level with the hardware requirements of different analog and digital components and interfaces between them, such as latches, MAX 232, a microcontroller and so on. The software for this system was implemented with the use of embedded system code written onto the microcontroller. And the designed and implementation is an efficient way to collect billings for electricity consumptions, which further facilitate the recharge process of meters currently being used to the generalization and the acceptability in other to revolutionaries the entire metering system used in the $21^{\text {st }}$ century.
\end{abstract}

Keywords: Intelligent GSM, Prepaid energy meter, and Microcontroller.

\section{Introduction}

\subsection{Overview}

Electric energy meters, the direct billing interface between utilities and consumers for long, have undergone several advancements in the last decade. The conventional electromechanical meters are being replaced by new electronic meters to improve accuracy in meter reading. Therefore, attempts are being made to automate the billing systems. Even though more accurate and faster meter readings have seen the light of day, bill payment is still based on an old procedure. They require the costumer to come to sales points of the electricity utility and buy electricity, where there are provided with vouchers (or tokens) that are then inserted back at home into the meter through a keypad. But the demand for computing power at all levels of electronic systems is driving advancements in semiconductor chip technology. The AMR and power quality monitoring systems manufacturers are taking advantage of these advances and integrating them into new meters and instruments. The networking technologies are driven by the demand for interconnection of computer users' worldwide (Jackson, 1996). The AMR and power monitoring systems are using these advances to expand the monitoring systems. The idea of prepaid metering will be very important for the new research fields of Micro-grid and Smart Grid and is an inevitable step in making any grid smarter than it is now. The system designed in this journal can be used to develop more complex system where a smart card can be used to several applications including prepayment (Koay, 2003).
In this paper, it was attempted to initiate a different idea of using mobile communication to remotely recharge as well as bill the consumer's energy consumption. A prepaid card capable of communicating with power utility using mobile communication is attached to the energy meter.( Kwan, 2002).

\subsection{Problem Statement}

Every time a customer (end-user of currently used meters) wants to recharge their energy meter, they would have to go all the way to the utility company to buy electricity and receive a voucher that is then must be taken back to the location of the meter and is entered through a keypad. This is a very tiresome process for electricity recharge, especially if the location of the meter is far from the utility company. Moreover, in case the electricity runs out, the period of time the building where the meter is installed stays offline until it is once more recharged may be critical depending on the facility itself (home, hospital, mainframe server...etc.).

The aim of the research is to automate the prepaid billing of energy meter. In this paper, the consumer end is user friendly and the customer recharges their balance at ease. At utility end, the retrieval of consumer balance becomes much easier and more accurate.

\subsection{Motivation}

An electricity meter provides an interface between the utility and the customer. Successfully implemented, this meter will benefit the end customer as well as the electric utility in that 


\section{International Journal of Science and Research (IJSR) \\ ISSN (Online): 2319-7064 \\ Index Copernicus Value (2013): 6.14 | Impact Factor (2014): 5.611}

the customer can recharge his account wirelessly from his home using an SMS to recharge. The device will show the remaining balance so that the user knows how much he has consumed and can plan ahead and know when he needs to refill the account and also provide the utility companies to collect the expenses from customers in advance, so that, they will no longer have to deal with late payments or non-paying bill by the customers. And also help to reduce electricity theft.( Ling et al , 2010).

\subsection{Aim and Objectives}

The aim of the project is to design and construct an intelligent prepaid energy meter that will be able to dictate any bypass by energy theft as well as to recharge the meter through GSM technology.

The objectives include:

i) To design a power supply unit, Voltage sensing device that automatically adjusts the power factor of the electricity supply through its calibration,

ii) To design a voltage sensing device that automatically adjusts the power factor of the electricity supply through its calibration and current sensing device to measure the accurate current consumed by the load

iii) To program a device using the AT-MEGA microcontroller that will measure current, voltage, and effectively calculate the power consumed from the load.

iv) To Program and configure the Global System for Mobile communication (GSM) module to effectively send, receive message which is compatible with all mobile network operators.

v) To design a circuit that disconnects the load when the unit is exhausted.

vi) To evaluate result based on the energy consumption of the measured values and the intelligent system

\subsection{Research Question}

i. Has the introduction of pre-paid energy meters contributed meaningfully in preventing bypass?

ii. What is the means of identification of total voltage availability in the building?

iii. How can bypass be detected?

iv. His the recharge of the intelligent prepaid meter successful by the use of SMS?

\section{Literature Review}

\subsection{Introduction}

Energy Meter is a device that measures the amount of electrical energy consumed by a residence, business, or an electrically powered device. They are typically calibrated in billing units and the most common one is the kilowatt hour, which is equal to the amount of energy used by a load of one kilowatt over a period of one hour, or 3,600,000 joules. Electricity meters operate by continuously measuring the instantaneous voltage (volts) and current (amperes) .The product of which gives the instantaneous electrical power (watts) which is then integrated against time to give energy used.
A Prepaid Energy Meter enables power utilities to collect electricity bills from the consumers prior to its consumption. The prepaid meter is also attributed with prepaid recharging ability and information exchange with the utilities pertaining to customer's consumption details.( Maheswari et al , 2009).

Over 40 countries have implemented prepaid meters in their markets. In United Kingdom the system, has been in use for well over 70 years with about 3.5 million consumers. The prepaid program in South Africa was started in 1992, since then they have installed over 6 million meters. Other African counties such as Sudan, Madagascar are following the South African success. The concept has found ground in Argentina and New Zealand with few thousands of installations. Countries such as Thailand, Bangladesh, Singapore, and Iran have been showing increased interest in adopting prepaid system.

In India, the State of West Bengal has decided to introduce the smart card operated prepaid energy meters in remote islands of Sunderbans. In Mumbai, pre-paid power is provided by the Brihanmumbai Electricity Supply and Transport (BEST) Undertaking.( Md et al , 2011).

\subsection{Evolution of Prepaid Energy Meters}

The use of electronic token prepayment metering has been widely used in UK for customers with poor record of payment. Ning et al (2004) in their paper presented the Digital Tele-wattmeter System as an example of a microcontroller- based meter. The meter was implemented to transmit data on a monthly basis to a remote central office through dedicated telephone line and a pair of modems. Maheswari et al (2009) utilized a DSP-based meter to measure the electricity consumption of multiple users in a residential area. A Personal Computer (PC) at the control center was used to send commands to a remote meter, which in turn transmitted data back, using the power Line Communication (PLC) technique. The major problem with this system is that it cannot detect tampering by consumers.

A paper suggests a design of a system which can be used for data transmission between the personal computer and smart card. The device will transmit the data in half duplex mode (Kwan, 2002). In this paper, an Intelligent Prepaid Energy Meter has been designed, modeled and simulated using Matlab/Simulink tools. Koay et al (2003) in their work (Koay .B.S, 2003), designed and implemented a Bluetooth energy meter where several meters are in close proximity, communicated wirelessly with a Master PC. Distance coverage is a major set-back for this kind of system because the Bluetooth technology works effectively at close range. In their paper,(Scaradozzi, 2003) Scaradozzi and Conte (2003) viewed home- automation systems as Multiple Agent Systems (MAS). Hong and Ning (2004) in their paper (Ning.L, 2004), proposed the use of Automatic Meter Reading (AMR) using wireless networks. Some commercial AMR products use the internet for data transmission. Stanescu et al (2006) present a design and implementation of SMS based control for monitoring systems (Stanescu, 2006). Prepayment poly-phase electricity metering systems have also been developed consisting of local prepayment and a card reader based energy meter (Ling Zou, 2010). In their 


\section{International Journal of Science and Research (IJSR) \\ ISSN (Online): 2319-7064 \\ Index Copernicus Value (2013): 6.14 | Impact Factor (2014): 5.611}

paper, Maheswari and Sivakumar (2009) (Maheswari \& Jejanthi, 2009) aimed to develop an energy efficient and low cost solution for street lighting system using Global System for Mobile communication [GSM] and General Packet Radio Service [GPRS].

The whole set-up provides the remote operator to turn off the lights when not required, regulate the voltage suppliedto the streetlights and prepare daily reports on glowing hours Sharma and Shoeb (2011), in their paper suggested a method where we utilize telecommunication systems for automated transmission of data to facilitate bill generation at the server end and also to the customer via SMS, e-mail :Amit.and Mohnish (2011) suggested in their paper, a prepaid energy meter behaving like a prepaid mobile phone. The meter contains a prepaid card analogous to mobile SIM card. The prepaid card communicates with the power utility using mobile communication infrastructure. Once the prepaid card is out of balance, the consumer load is disconnected from the utility supply by the contactor. The power utility can recharge the prepaid card remotely through mobile communication based on customer requests.

\section{Research Methodology}

\subsection{Introduction}

This Research is useful for billing purposes in Electricity board. Instead of going to every house and taking the readings or using a token, by just sending an SMS the readings of the house can be received and the electric bill can be recharged. The microcontroller and the GSM unit are interfaced with the energy meter of each house. Every house has a separate number, which is given by the corresponding authority. The GSM unit is fixed in the energy meter. The amount of consumption is stored in the microcontroller's memory and available to the authority as SMS. Using this software, SMS can be sent through the GSM Modem to that particular number which is assigned by these authorities and wait for the response. On other end, the modem will receive the data in the form of a command and informs the controller to do the readings. After the readings the controller will send data to the modem. The modem, in turn sends data to the other end. In the office the GSM unit will receive the data and the total consumption information. The number assigned by the authorities is unique. Using GSM, the response can be obtained very fast, due to which time is saved. After consumption of the entire balance on the meter, the power will be cut-off, and the consumer must send an SMS to recharge. This will reduce illegal power using without paying money, and also able to solve by - pass of voltage.

The system gives the information of meter reading, power cut, total unit used, unit left, power disconnect, and tampering on request or regularly at a particular interval through SMS. Information is sent and received by the energy providing company such as PHCN (Power Holding Company of Nigeria) using the Global System for Mobile Communication (GSM) Network.

A quad band GSM modems with a registered SIM (subscriber identification module) card with unique numbers is used. The communication process employed here is achieved by installing sets of AT (Attention) command strings in the GSM modems through HyperTerminal software which comes with Microsoft operating system. With the aid of the installed AT command strings, instructions and data are sent and received by the GSM modems respectively. Data received from the consumer unit are used to update the customer's database at the office of the power providing company. The EEPROM of the microcontroller is updated each time a customer pays his/her bills via SMS recharge by simply sending a secret pin from his mobile number to the developed system. Other information such as total energy consumed, total amount paid on consumption, User's interface consist of LCD (Liquid Crystal Display) which displays energy consumed, the (unit recharged) amount of bill paid and the amount left to be used. Information such as unit recharged, success of recharge, power disconnect/reconnect by the supply company, and when the unit left is critically low to avoid loss of power supply is communicated through the customer's mobile phone to the customer via SMS. With this new system, customers are confident that they are not being exploited, power pilfering is eliminated, rogue customers are shut off, prevention of bypass and the huge revenue loss which was inherent in the traditional metering system is completely avoided. For the programming and development of the controller part of the project at the energy meter end was made possible by the use of ATMega32 microcontroller. It is inexpensive, simple, cross platform and has other extensible properties. The microcontroller has a flash memory of $32 \mathrm{kB}$, making the processing speed fast enough for the single IC to cater to not just one but multiple microcontrollers in a residential building.

The software section contains the embedded ' $\mathrm{C}$ ' and assembly Language program consisting of a string of 'AT' command set and other instruction set to make the whole system workable. The ' $\mathrm{C}$ ' source code was transferred to a Keil compiler software for conversion to 'Hex file', and then to the microcontroller. This section also contains the simulation of the whole system which was done with Proteus ISIS professional version 7.8 SP2.

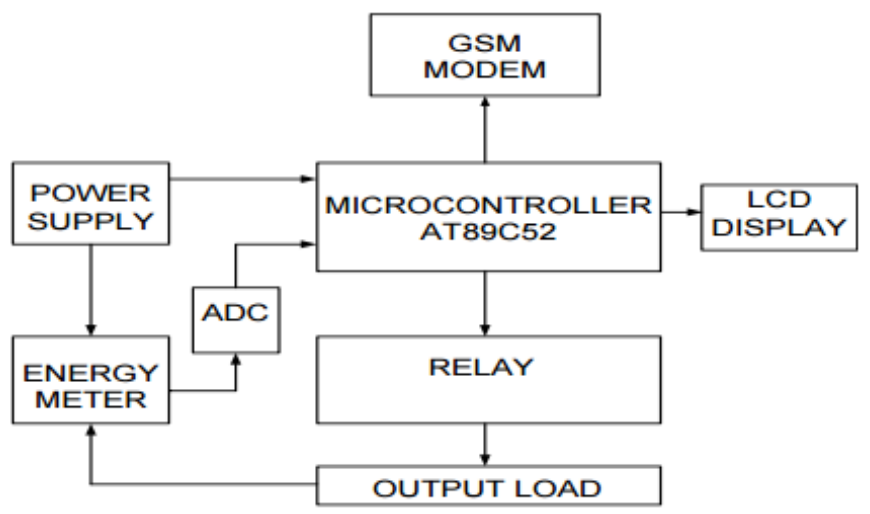

Figure 3.1: Block diagram of the prepaid energy meter with rechargeable option

Source: Designed with smart draw software (www.smartdraw.com) 


\subsection{Design of the Power Supply Unit}

When an AC signal is applied to the primary coil of the transformer, due to the magnetic effect of these conductors magnetic flux is induced in these conductors (primary) and this flux is transferred to the secondary conductors by the transformer action. Transformer is an electromechanical static device which transformer electrical energy from one conductors to another without any change in its frequency. Here the diodes are connected in a bridge section. The secondary conductors of the transformer is given to the bridge circuit for the purpose of rectification.

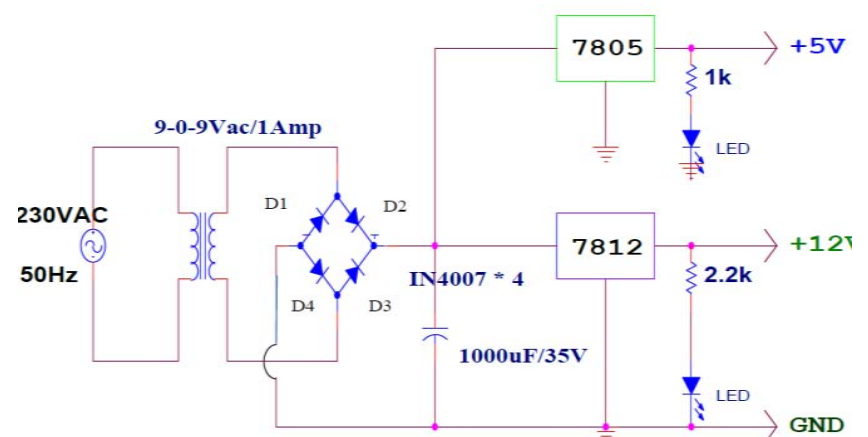

Figure 3.2: Connection diagram of power supply

3.3 Design of a voltage sensing device that automatically adjusts the power factor of the electricity supply through its calibration.

The voltage sensor is needed to measure voltage and the phase angle of the voltage across the load accurately, and is expected to behave linearly in some specific voltage range. The voltage sensor module was designed to be connected to the main power on the input side and to the Energy Meter IC on the output side

3.4 Design of a current sensing device to measure the accurate current consumed by the load.

The current sensor is needed to monitor the current flow by measuring and reporting the actual current usage and the current phase angle to the microcontroller. It is also needed to operate accurately and linearly in order to obtain the accurate usage and consequently the accurate power usage. It is expected to be able to hold the maximum current of 10 Amperes. The current sensor was designed to connect directly to the load on the input side and to the Energy Meter IC on the output side. The input to the entity is the value of the voltage drop across a shunt resistor and the output to the meter IC is the voltage that is proportional to the input voltage. The ratio of the input and output voltage would depend on the model of the current transformer used in the circuit.(Ankit Chandak, 2011)

\subsection{DESIGN OF SMS CONTROLLER UNIT}

GSM module transmits user's account information from power meter to utility company and also receives data from utility company. The SIM900 is a complete Quad-band GSM/GPRS solution in a SMT module which can be embedded in the customer applications.
Features of SIM900

i. SIM900 is designed with a powerful single-chip processor integrating AMR926EJ-S core.

ii. Quad-band GSM/GPRS module with a size of $24 \mathrm{~mm}$ X $24 \mathrm{~mm}$ X $3 \mathrm{~mm}$.

iii. SMT type suit for customer application.

An embedded powerful TCP/IP protocol stack

3.6 Programming of a device using the AT-MEGA microcontroller that will measure current, voltage, and effectively calculate the power consumed from the load.

Algorithm for Energy Metering system at consumer's end

1. Start

2. Initialize the display and RTC.

3. Display date and time.

4. Check GSM Connection and set to Text Mode.

5. If GSM disconnected, display that on LCD and turn LED OFF, otherwise turn ON.

6. Receive User number and set it for communication.

7. Decide whether the number of units in Microcontroller is sufficient or not. If the balance is insufficient then disconnect the load from supply and send message to user number notifying of balance recharge otherwise connect to the load to supply.

8. Count the number of pulses initiated from inbuilt ADC when theload consumes power.

9. Measure time with the help of timer1.

10. Calculate power, $P=3000 \mathrm{x} X$ using this equation, where $\mathrm{X}$ denotes the frequency of pulses that is produced by the microcontroller.

11. Calculate energy

12. Store energy and power reading into the EEPROM of ATmega32 Microcontroller for future use.

13. Check for updates from GSM for rate updates according to real time.

\subsection{Design Flowchart}




\section{International Journal of Science and Research (IJSR) \\ ISSN (Online): 2319-7064}

Index Copernicus Value (2013): 6.14 | Impact Factor (2014): 5.611

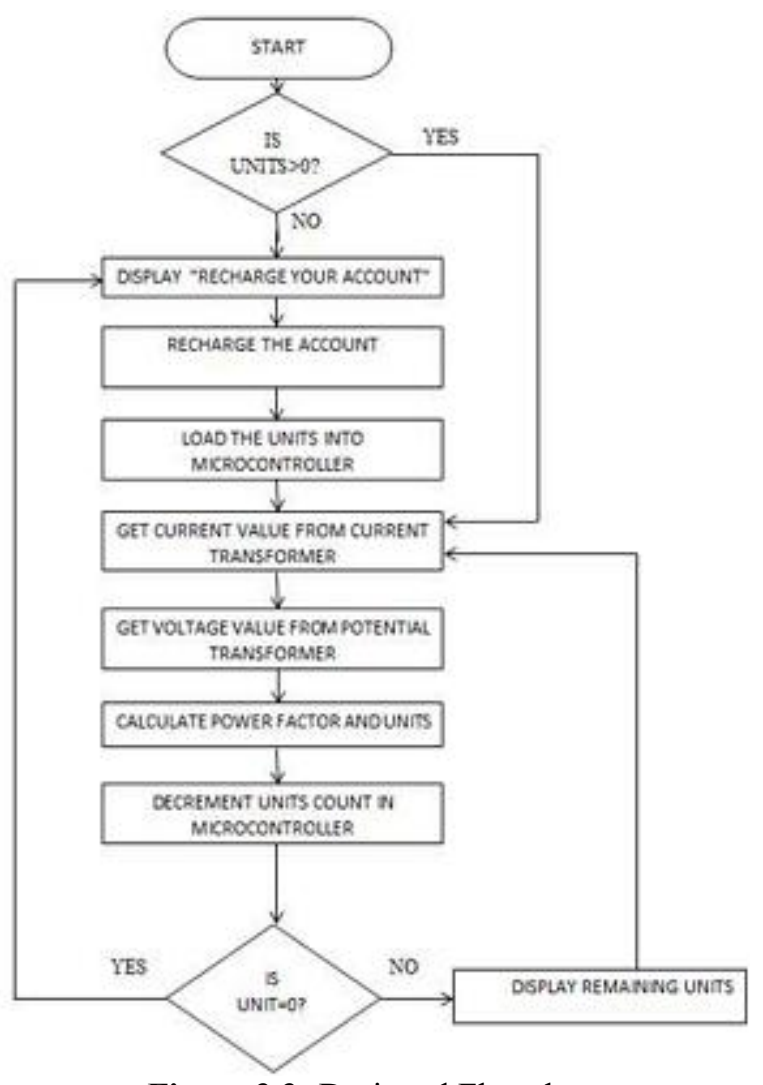

Figure 3.3: Designed Flowchart

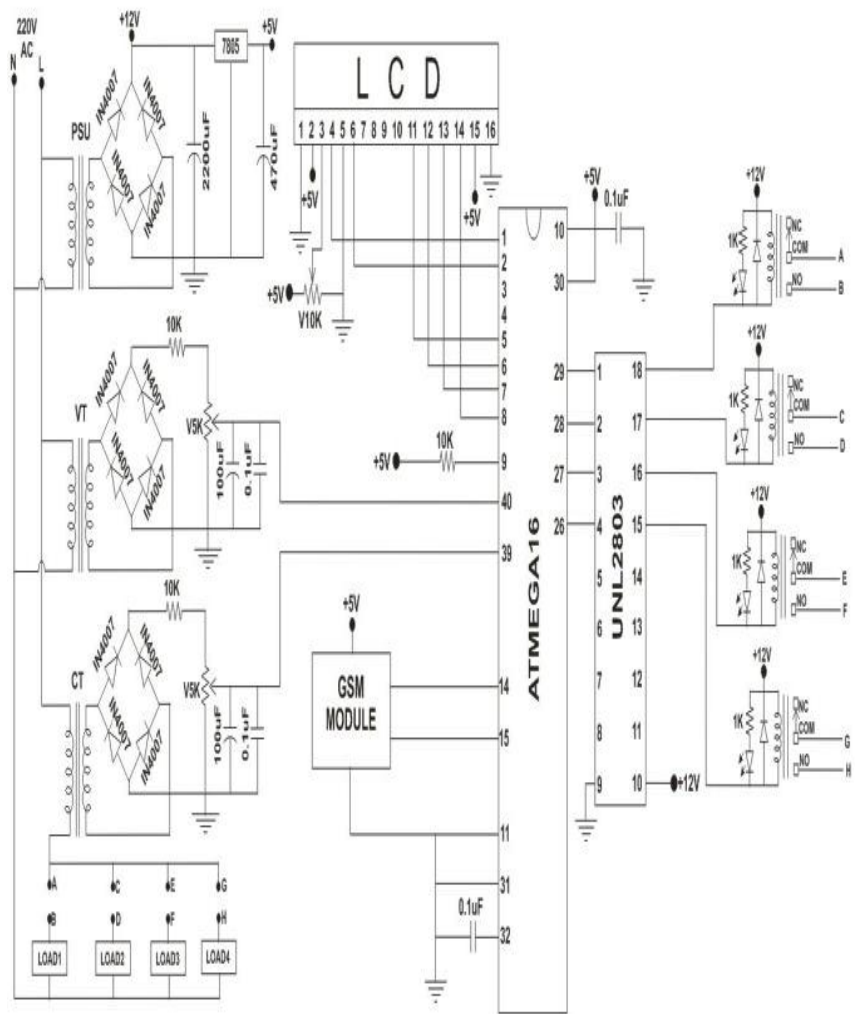

Figure 3.4: Complete Circuit Diagram

\subsection{Implementation of the Software}

For the software part we use an algorithm and is given below

i) The controller continuously scans the ports which receive inputs from maximum demand section and optical section.

ii) If the optical pickup receives a pulse then the counter increments and display the unit consumed in LCD. Then count is compared to display the warning for recharging.

iii) When the total unit finishes, after that the tripping relay is activated to disconnect the power.

iv) If the maximum demand section gives a pulse then it activates the tripping mechanism.

Continuously the controller rechecks the maximum demand section and regains the power when load is reduced

\section{System Implementation and Analysis}

\subsection{Calculation and Result}

\subsection{System Testing}

The circuit was connected, with the exception that the relay, load and CT are connected together. The line connecting the load to the main supply goes through the CT first (primary windings). Between the CT and the load, the relay is connected to disconnect the power in case the user runs out of balance, and finally the line is connected back to the neutral. The complete final code was written into the MCU, controlling the operation of the entire system, and it was run to test the meter. Figure 4.12 shows the complete meter circuit.

Energy is the total power delivered or consumed over a time interval,

That is Energy $=$ Power $\mathrm{x}$ Time

Power $=$ voltage $\mathrm{x}$ current $\mathrm{x}$ power factor

The Energy Meter was tested with four Electric bulb of 220 volt was used as a load with $0.4 \mathrm{~A}$ current. The supply voltage was between $210 \mathrm{~V}$ and $230 \mathrm{~V}$. Energy measurement process is described step by step.

Table 1: Test result of Energy measurement by proposed prepaid Energy meter. Here power $=60$ watt 


\section{International Journal of Science and Research (IJSR) \\ ISSN (Online): 2319-7064}

Index Copernicus Value (2013): 6.14 | Impact Factor (2014): 5.611

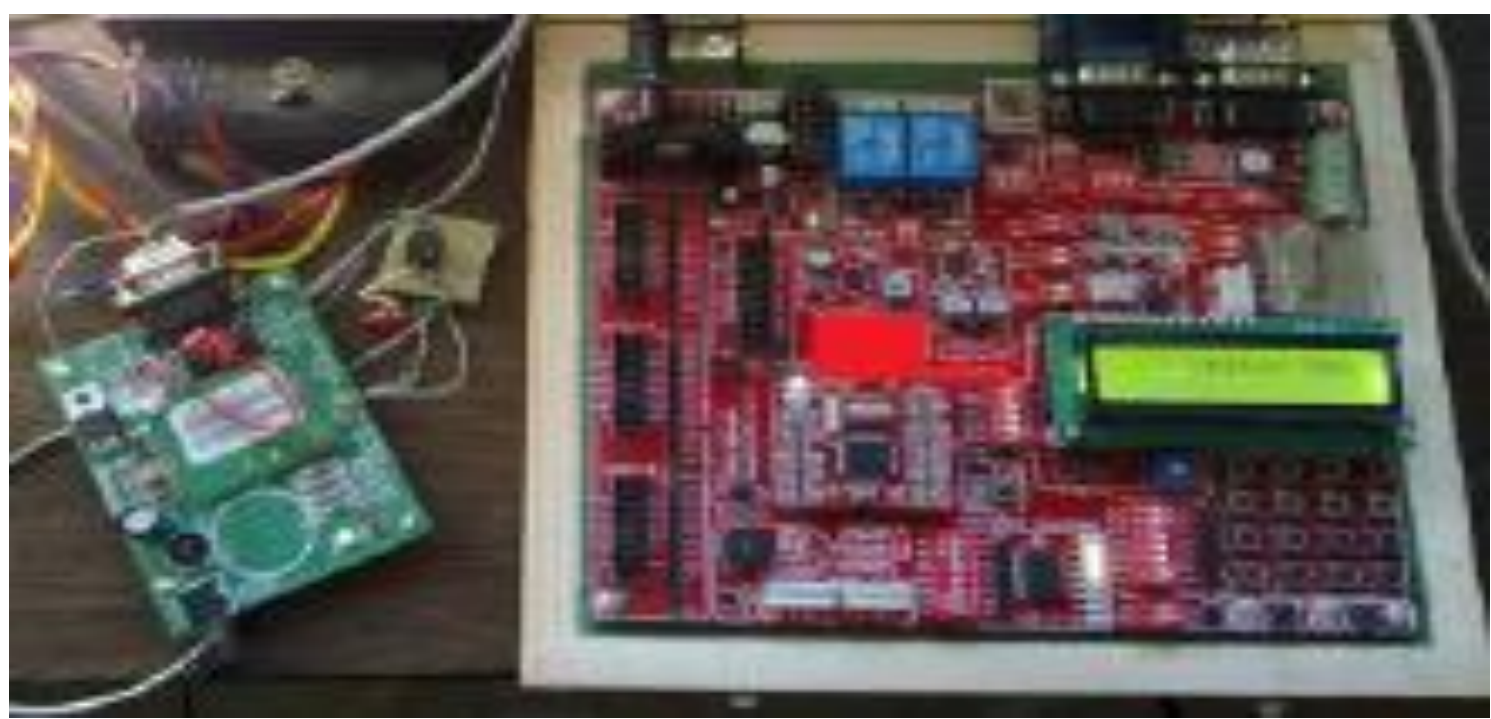

Figure 4.1: Complete Intelligent Energy Meter Circuit

\subsection{LCD DISPLAY AT NO LOAD AND ZERO UNIT BALANCE.}

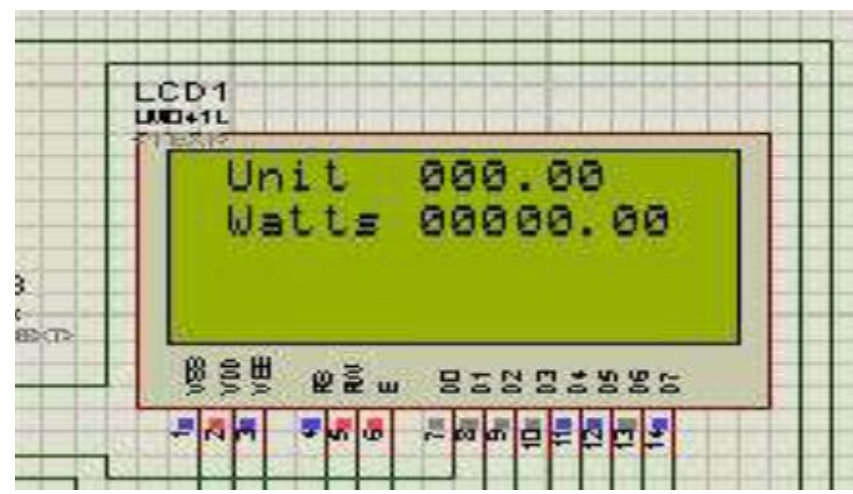

Figure 4.2: LCD Display at No load and zero unit balance

\subsection{LCD DISPLAY AT LOAD AND ABOVE ZERO UNIT BALANCE STATE}

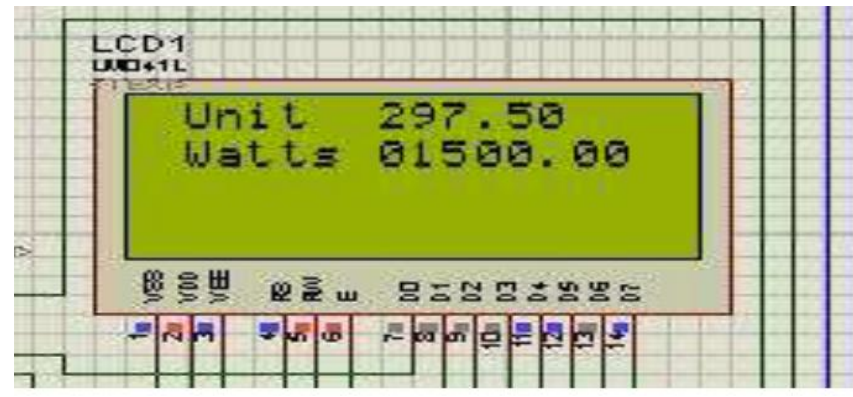

Figure 4.3: LCD Display at Load and above Zero unit balance state

Result of SMS sents

\begin{tabular}{|c|c|c|}
\hline $\begin{array}{c}\text { TIME } \\
(\mathrm{Sec})\end{array}$ & $\begin{array}{c}\text { Expected Energy Meter } \\
\text { Output }(\text { Watt-Sec) }\end{array}$ & $\begin{array}{c}\text { Energy Output from } \\
\text { Measurement }\end{array}$ \\
\hline 0 & 0 & 0 \\
\hline 20 & 125 & 120 \\
\hline 40 & 240 & 240 \\
\hline 60 & 355 & 360 \\
\hline 80 & 490 & 480 \\
\hline 100 & 6000 & 6000 \\
\hline 120 & 7100 & 7200 \\
\hline 140 & 8500 & 8400 \\
\hline
\end{tabular}

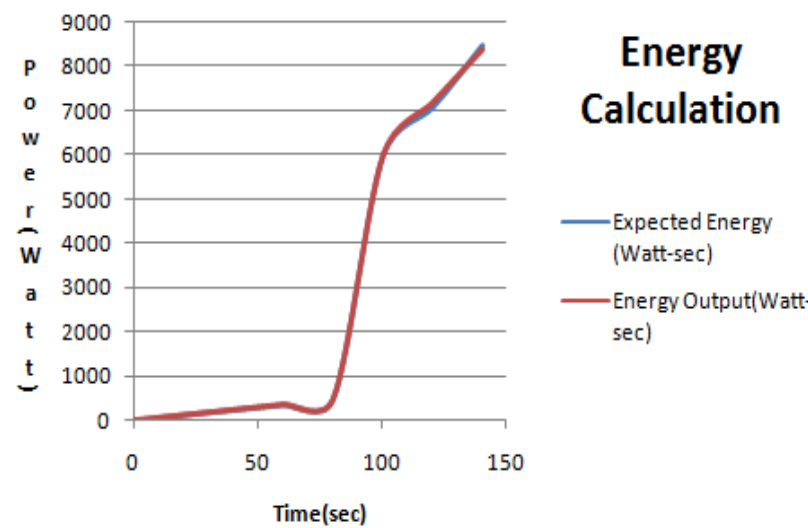

Figure 4.3: Energy Calculation

From Fig 4.3, the blue symbol (expected energy) is the intelligence, the system calculate the energy consumption automatically by using current sensor to get the current readings and voltage sensor to get the voltage readings. The result was then store in log over certain period of time to get the energy consumption. The brown symbol is the expected output from manual measurement. It can be proved that the intelligence shows slight variation with the manual system

\section{Conclusion and Future Recommendations}

\subsection{Conclusion}

This proposed simple and economic digital prepaid energy meter controlled by GSM based communication can cover rural area as well as urban areas. This is an effort about improving the present conventional electromechanical meters through the fusion of analog and digital circuits which have aim of collecting bills for consumption of power thus improved the revenue collection for scheduled supply. This is beneficial for Nigeria like developing country which having huge population for improving economic through power utility.

\subsection{Recommendations and Future Work}

The development of GSM based energy meter demonstrates the concept and implementation of new power metering

Volume 5 Issue 1, January 2016

www.ijsr.net 


\section{International Journal of Science and Research (IJSR) \\ ISSN (Online): 2319-7064}

Index Copernicus Value (2013): 6.14 | Impact Factor (2014): 5.611

system. GSM based AMR have low infrastructure cost, low operating costs, more data security and less man power required. It not only solve the problem of manual meter reading but also provide additional feature such as power disconnect, power connect, power cut alert and tempering alert customer can also pay bill via online login on authenticated web. Data base server can stored the current month data and also all previous month data for future use. So it saves a lot amount of time and energy. Furthermore this can whole contribute towards smarter grid system

\section{References}

[1] Jackson.C, S. a. (1996). A microprocessor based digital wattmeter system design. 31st Intersociety

[2] Conference on Energy Conversion Engineering.

[3] Koay .B.S, C. S. (2003). Design and implementation of a Bluetooth energy meter. the Joint 4th

[4] International Conference on Information, Communication and Signal Processing and the 4th Pacific Rim Conference on Multimedia.

[5] Kwan, B. M. (2002). PIC Based Smart Card Prepayment System. Student Conference on Research

[6] and Development.

[7] Ling Zou, S. C. (2010). The Design of Prepayment Polyphase Smart Electricity Meter System.

[8] International Conference on Intelligent Computing and Integrated Systems (ICISS).

[9] Maheswari, C., \& Jejanthi, R. (2009). Implementation of Energy Management Structure for street

[10] Lighting System. Journal of Modern Applied Science.

[11] Md. Mejbaul Haque, M. K. (2011). Microcontroller Based Single Phase Digital Prepaid Energy meter.

[12] Ning.L, H. L. (2004). Design and Implementation of Remote Intelligent Management System for City

[13] Energy Resources base on Wireless Network.

[14]P. Harish M.Tech, S. S. (2012). GSM Based Automatic Wireless Energy Meter Reading System.

[15] International Journal of Engineering Research \& Technology (ERT). 